\title{
Improved synthesis and characterisation of 1,3,4-oxadiazole
}

\author{
Kati M. Aitken and R. Alan Aitken* \\ EaStCHEM School of Chemistry, University of St Andrews, North Haugh, \\ St Andrews, Fife, KY16 9ST, United Kingdom \\ E-mail: raa@st-and.ac.uk
}

\section{Dedicated to Professor Ferenc Fülöp on the occasion of his 60th birthday}

\begin{abstract}
Synthetic approaches to 1,3,4-oxadiazole have been investigated and an improved method involving dehydration of $N, N^{\prime}$-diformylhydrazine with $\mathrm{P}_{2} \mathrm{O}_{5}$ in polyphosphoric acid is described. The ${ }^{13} \mathrm{C}$ NMR spectrum of this compound is reported for the first time including determination of ${ }^{l} J_{\mathrm{C}-\mathrm{H}}$ and ${ }^{3} J_{\mathrm{C}-\mathrm{H}}$.
\end{abstract}

Keywords: 1,3,4-Oxadiazole, cyclodehydration, polyphosphoric acid, $N, N$ '-diformylhydrazine, ${ }^{13} \mathrm{C}$ NMR

\section{Introduction}

In the context of recent experimental and computational studies on the high resolution vibrational spectra of some fundamental heterocyclic compounds, ${ }^{1-6}$ we needed to prepare $1,3,4$ oxadiazole 1. ${ }^{7}$ Although this simple compound was first reported in $1965,{ }^{8}$ only one method has ever been described for its preparation, ${ }^{9}$ and this involves thermal elimination of ethanol from compound 2 , itself formed by reaction of $N$-formylhydrazine with triethyl orthoformate (Scheme 1). We have found this method to be unsatisfactory in various ways. The preparation of 2 must be carefully controlled to avoid formation of a 1,2,4-triazole byproduct, ${ }^{9}$ it exists as a mixture of different $E / Z$ isomers leading to complex, and as yet unexplained, NMR spectra and problems in obtaining it in pure crystalline form, and the final thermolysis reaction, reported to proceed in "about $50 \%$ yield", " was found to be unpredictable and to give yields in our hands ranging from $0-10 \%$. We therefore set out to develop a more convenient synthesis and describe here the results. 


\section{Results and Discussion}

We first re-examined the literature method in an attempt to overcome the problems encountered. In our hands, heating the solid compound $\mathbf{2}$ above its melting point under atmospheric pressure and collecting the liquids which distilled off afforded mainly ethanol and ethyl formate with $<1 \%$ yield of 1 . The use of various methods that would favour the intramolecular cyclisation with loss of EtOH as opposed to intermolecular reactions leading to polymerisation was attempted. Moving to vacuum distillation and mixing the compound 2 with an inert solid such as $\mathrm{SiO}_{2}$ was of little benefit. Flash Vacuum Pyrolysis (FVP), which involves passing the substrate through a furnace in a flow system under high vacuum, is well known as a method for clean and efficient extrusion reactions where polymerisation is to be avoided. This did result in a significant improvement with 1 being obtained in a reproducible $10 \%$ yield upon FVP at $600-700{ }^{\circ} \mathrm{C}$, but the yield was still disappointing so attention was turned to alternative methods avoiding 2 .

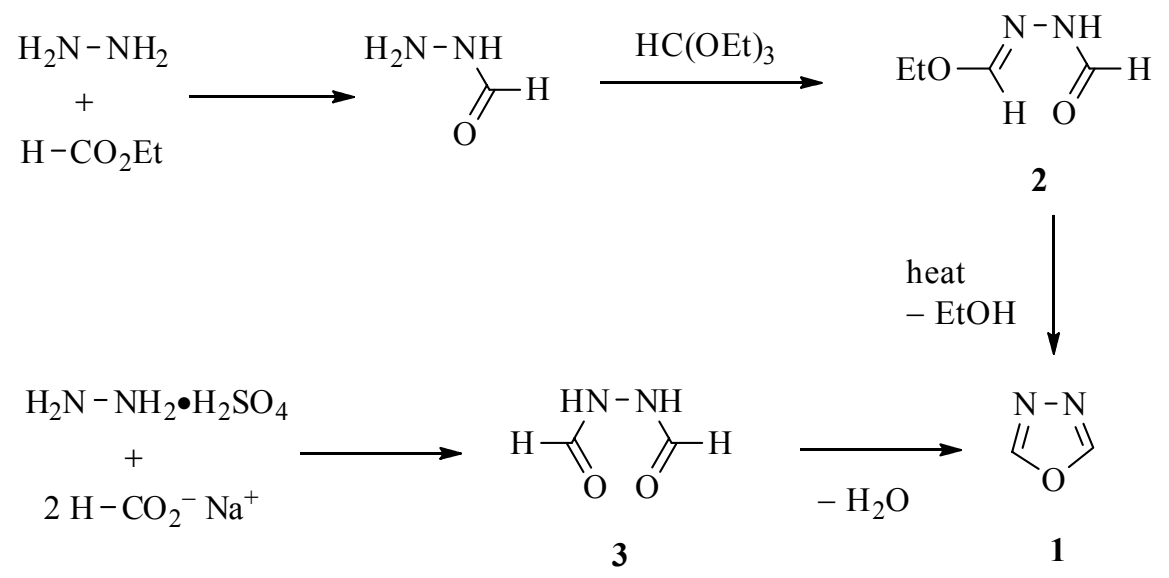

\section{Scheme 1}

An attractive alternative approach involves the cyclodehydration of the readily available $N, N^{\prime}$-diformylhydrazine $\mathbf{3}$ but, although this is a well known route to oxadiazoles in general, ${ }^{10}$ it does not seem to have been reported for the parent heterocycle. Exposure of compound $3,{ }^{11}$ to a variety of standard dehydration reagents and conditions showed that the desired transformation was not easily achieved (Table 1, entries 1-12). Part of the problem was that the methods tried for dehydrative cyclisation frequently involved acidic conditions under which the target product would be protonated. A basic work up followed by extraction was therefore used but this sometimes resulted in hydrolysis of the compound. The first sign of success came from treatment with $\mathrm{P}_{2} \mathrm{O}_{5}$ in toluene (entry 13). By moving to polyphosphoric acid, a much better result was achieved (entry 14), but we were concerned to find that repeating this reaction with newly purchased polyphosphoric acid gave no product (entry 15). The problem was eventually traced to the fact that the original polyphosphoric acid was dehydrated with a crust of solid around the bottle and this effect could be duplicated by addition of $10 \% \mathrm{w} / \mathrm{w}$ of $\mathrm{P}_{2} \mathrm{O}_{5}$ to new polyphosphoric 
acid (entry 16). Even with this reagent, the reaction time proved to be critical with too long a reaction time again leading to no product (entry 17). The other important aspect was found to be the work-up. Initially we neutrallised the reaction mixture with aqueous $\mathrm{NaOH}$ before extracting with $\mathrm{CH}_{2} \mathrm{Cl}_{2}$ but it was later found to be better to use the milder base $\mathrm{NaHCO}_{3}$ to minimise losses through hydrolytic breakdown of product 1 .

Table 1. Conversion of $\mathbf{3}$ into $\mathbf{1}$

\begin{tabular}{|c|c|c|c|}
\hline Entry & Reagents & Conditions & Yield of $1(\%)$ \\
\hline 1 & - & $\mathrm{FVP}, 500-800^{\circ} \mathrm{C}$ & $1-2$ \\
\hline 2 & $4 \AA$ Molecular sieves & toluene, reflux $4 \mathrm{~h}$ & 0 \\
\hline 3 & $4 \AA$ molecular sieves, Amberlite R-120 & toluene, reflux $12 \mathrm{~h}$ & 0 \\
\hline 4 & $\left(\mathrm{CF}_{3} \mathrm{CO}\right)_{2} \mathrm{O}, \mathrm{CF}_{3} \mathrm{CO}_{2} \mathrm{H}$ & reflux, $4 \mathrm{~h}$ & 0 \\
\hline 5 & $\mathrm{Ac}_{2} \mathrm{O}, \mathrm{AcOH}$ & reflux $4 \mathrm{~h}$ & 0 \\
\hline 6 & 10 equiv. $\mathrm{SOCl}_{2}$, hexane & reflux, $3 \mathrm{~h}$ & 0 \\
\hline 7 & $\mathrm{ClCOCOCl}, \mathrm{CH}_{2} \mathrm{Cl}_{2}$ & reflux, $8 \mathrm{~h}$ & 0 \\
\hline 8 & 6 equiv. conc. $\mathrm{H}_{2} \mathrm{SO}_{4}$ & $0{ }^{\circ} \mathrm{C}, 2 \mathrm{~h}$ then $\mathrm{RT}, 2 \mathrm{~h}$ & 0 \\
\hline 9 & DCCI, $\mathrm{CH}_{2} \mathrm{Cl}_{2}$ & $\mathrm{RT}, 40 \mathrm{~h}$ & 0 \\
\hline 10 & DCCI, MeCN & reflux, $7 \mathrm{~h}$ & 0 \\
\hline 11 & DEAD, $\mathrm{Ph}_{3} \mathrm{P}, \mathrm{THF}$ & reflux, $8 \mathrm{~h}$ & 0 \\
\hline 12 & 5 equiv. $\mathrm{P}_{2} \mathrm{O}_{5}$, THF & reflux, $48 \mathrm{~h}$ & 0 (THF reacts) \\
\hline 13 & $\mathrm{P}_{2} \mathrm{O}_{5}$, toluene & reflux, $4 \mathrm{~h}$ & $<5$ \\
\hline 14 & polyphosphoric acid (old) & $100^{\circ} \mathrm{C}, 8 \mathrm{~h}$ & 30 \\
\hline 15 & polyphosphoric acid (new) & $100^{\circ} \mathrm{C}, 8 \mathrm{~h}$ & 0 \\
\hline 16 & polyphosphoric acid (new) $+10 \% \mathrm{P}_{2} \mathrm{O}_{5}$ & $100^{\circ} \mathrm{C}, 4 \mathrm{~h}$ & 30 \\
\hline 17 & polyphosphoric acid (new) $+10 \% \mathrm{P}_{2} \mathrm{O}_{5}$ & $100^{\circ} \mathrm{C}, 18 \mathrm{~h}$ & 0 \\
\hline
\end{tabular}

By using these conditions we have been able to prepare multi-gram quantities of 1,3,4oxadiazole as required for spectroscopic investigation, and the high-resolution vibrational spectra have already been published. ${ }^{7}$ Compound 1 is a colourless liquid with bp $150{ }^{\circ} \mathrm{C}$ and shows a ${ }^{1} \mathrm{H}$ NMR signal in $\mathrm{CDCl}_{3}$ at $\delta_{\mathrm{H}} 8.52$ (Lit., ${ }^{8} 8.73$ ). We were surprised to discover that, despite detailed studies of the ${ }^{15} \mathrm{~N}$ and ${ }^{14} \mathrm{~N}$ NMR spectra having been reported some time ago, ${ }^{12,13}$ the ${ }^{13} \mathrm{C}$ NMR spectrum of this fundamental heterocyclic compound has apparently remained unreported until now. The observed chemical shift of $\delta_{\mathrm{C}} 152.7$ is in good agreement with values reported for similar compounds such as C-2 of oxazole $\left(\delta_{\mathrm{C}} 151.2\right)^{14}$ and thiazole $\left(\delta_{\mathrm{C}} 152.8\right) .{ }^{14}$ By recording the undecoupled ${ }^{13} \mathrm{C}$ NMR spectrum, the $\mathrm{C}-\mathrm{H}$ coupling constants were determined as ${ }^{1} J_{\mathrm{C}-\mathrm{H}}=$ $234 \mathrm{~Hz}$ and ${ }^{3} J_{\mathrm{C}-\mathrm{H}}=5 \mathrm{~Hz}$.

Finally, we were attracted by the recent reports of Ramazani and Souldozi, ${ }^{15,16}$ that aromatic carboxylic acids may be converted directly into 2-aryl-1,3,4-oxadiazoles under mild conditions by treatment with isocyanoiminotriphenylphosphorane, $\mathrm{Ph}_{3} \mathrm{P}=\mathrm{N}-\mathrm{N}=\mathrm{C}$ : . This phosphinimine was 
readily prepared, ${ }^{17}$ but unfortunately attempts to react it with formic acid under a wide variety of conditions gave no trace of 1,3,4-oxadiazole 1.

\section{Experimental Section}

General. NMR spectra were obtained for ${ }^{1} \mathrm{H}$ at $300 \mathrm{MHz}$ and for ${ }^{13} \mathrm{C}$ at $75 \mathrm{MHz}$ using a Bruker AM300 instrument. All spectra were run on solutions in $\mathrm{CDCl}_{3}$ with internal $\mathrm{Me}_{4} \mathrm{Si}$ as reference. Chemical shifts are reported in ppm to high frequency of the reference and coupling constants $J$ are in Hz. $\mathrm{N}$-Formylhydrazine was prepared from ethyl formate and hydrazine hydrate using the reported method ${ }^{18}$ and converted into compound $\mathbf{2}$ as described. ${ }^{9} N, N^{\prime}$-Diformylhydrazine $\mathbf{3}$ was prepared from hydrazine sulfate and sodium formate using the literature method. ${ }^{11}$

1,3,4-Oxadiazole (1). Polyphosphoric acid (18.0 g) was stirred at $80-100{ }^{\circ} \mathrm{C}$ while $\mathrm{P}_{2} \mathrm{O}_{5}(2.0 \mathrm{~g})$ was added, followed after $15 \mathrm{~min}$ by $N, N^{\prime}$-diformylhydrazine $3(2.0 \mathrm{~g}, 35.7 \mathrm{mmol})$. The mixture was stirred at $100{ }^{\circ} \mathrm{C}$ for $4 \mathrm{~h}$ and then added to ice $(100 \mathrm{~g})$. The resulting mixture was neutrallised by addition of $\mathrm{NaHCO}_{3}(13.8 \mathrm{~g})$ and then extracted with $\mathrm{CH}_{2} \mathrm{Cl}_{2}\left(3 \times 50 \mathrm{~cm}^{3}\right)$. Drying and evaporation of the extract gave the product $(0.42 \mathrm{~g}, 30 \%)$ as a colourless liquid, bp $\sim 150{ }^{\circ} \mathrm{C} ; \delta_{\mathrm{H}} 8.52(2 \mathrm{H}, \mathrm{s}) ; \delta_{\mathrm{C}} 152.7 ; \delta_{\mathrm{C}}$ (undecoupled) 152.7 (dd, $\left.J 234,5\right) ;$ HRMS (CI) Calcd. for $\mathrm{C}_{2} \mathrm{H}_{3} \mathrm{~N}_{2} \mathrm{O}(M+\mathrm{H}): 71.0245$. Found: 71.0247 .

\section{References and Notes}

1. Hegelund, F.; Wugt Larsen, R.; Aitken, R. A.; Kraus, H.; Palmer, M. H. Molecular Physics 2004, 102, 1583.

2. Hegelund, F.; Wugt Larsen, R.; Aitken, R. A.; Palmer, M. H. J. Mol. Spectrosc. 2005, 233, 256.

3. Hegelund, F.; Wugt Larsen, R.; Aitken, R. A.; Palmer, M. H. J. Mol. Struct. 2006, 780-781, 45 .

4. Hegelund, F.; Wugt Larsen, R.; Aitken, R. A.; Palmer, M. H. J. Mol. Spectrosc. 2006, 236, 189.

5. Hegelund, F.; Wugt Larsen, R.; Aitken, R. A.; Palmer, M. H. J. Mol. Spectrosc. 2008, 248, 161.

6. Hegelund, F.; Wugt Larsen, R.; Aitken, R. A.; Melec, P.; Palmer, M. H. J. Mol. Spectrosc. 2008, 250,8 .

7. Hegelund, F.; Wugt Larsen, R.; Aitken, R. A.; Aitken, K. M.; Palmer, M. H. J. Mol. Spectrosc. 2007, 246, 198.

8. Ainsworth, C. J. Am. Chem. Soc. 1965, 87, 5800.

9. Ainsworth, C.; Hackler, R. E. J. Org. Chem. 1966, 31, 3442. 
10. Weaver, G. W. In Science of Synthesis, Storr, R. C.; Gilchrist, T. L. Eds.; Thieme: Stüttgart, 2003; Vol. 13, Ch. 8, pp 219-252.

11. Pellizzari, G. Real. Accad. dei Lincei 1899, 8, 327-332; Chem. Abstr. 1906, 0, 97076.

12. Stefaniak, L.; Roberts, J. D.; Witanowski, M.; Webb, G. A. Org. Magn. Reson. 1984, 22, 215.

13. Witanowski, M.; Biedrzycka, Z.; Sicinska, W.; Grabowski, Z.; Webb, G. A. J. Magn. Reson., Ser. A 1996, 120, 148.

14. Bocian, W.; Jazwinski, J.; Sadlej, A. Magn. Reson. Chem. 2008, 46, 156.

15. Souldozi, A.; Ramazani, A. Tetrahedron Lett. 2007, 48, 1549.

16. Ramazani, A.; Souldozi, A. Arkivoc 2008, (xvi), 235.

17. Stolzenberg, H.; Weinberger, B.; Fehlhammer, W. P.; Pühlhofer, F. G.; Weiss, R. Eur. J. Inorg. Chem. 2005, 4263.

18. Pellizzari, G. Gazz. Chim. Ital. 1894, 24, 222. 